\title{
Leadership and Mediation in Risk Contexts: New Actors and Models of Intervention
}

\author{
Mariana Dias $^{\mathrm{a} *}$, Lia Pappamikail ${ }^{\mathrm{b}}$, Maria João Carvalho ${ }^{\mathrm{c}}$ \\ * Corresponding author: Mariana Dias,marianad@eselx.ipl.pt \\ ${ }^{\text {a }}$ Escola Superior de Educação do Instituto Politécnico de Lisboa and UIDEF, Instituto de Educação, Universidade de Lisboa, \\ Campus do IPL de Benfica Lisboa, Portugal, marianad@eselx.ipl.pt \\ ${ }^{\mathrm{b}}$ Escola Superior de Educação do Instituto Politécnico de Santarém, Complexo Andaluz, Santarém, Portugal, \\ lia.pappamikail@gmail.com

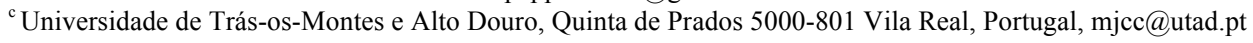

\begin{abstract}
http://dx.doi.org/10.15405/epsbs.2016.11.49

This article aims to analyze the program Network of Mediators of Capacitation for Academic Achievement which has been presented in international agencies of great prestige as a model of "good practices." The program, which is promoted by the EPIS Association, founded by a group of Portuguese entrepreneurs under the theme of social inclusion, presents itself as an innovative model of solidarity and social capacitation of young people under risk of academic underachievement and school withdrawal. The research we have carried out focuses on the following aspects: the objectives of the EPIS Association, the work methodology of the Network of Mediators and the manner in which it is developed and envisioned on the field. The study, which is qualitative in nature, is based on the analysis of a vast documental compilation and interviews with actors which are more directly involved with the program (head teachers, mediators, and local authorities). The results of the study show that the program under analysis favours a highly structured intervention which, although generally valued and considered effective, does not concede a wide margin of leadership, autonomy, and participation to local actors. On a deeper analytical level, the study shows that the creation of the Association and program under analysis is included in the affirmation process of new forms of governance and public action in Portugal, namely the affirmation of "new philanthropies" on education, a tendency with scarce tradition in the country.
\end{abstract}

(C) 2016 Published by Future Academy www.FutureAcademy.org.uk

Keywords: Leadership, Mediation, New Philanthropies. 


\section{Introduction: state, civil society and the private sector in Portugal}

Portugal has a century-old tradition of centralization in terms of educational policy which has not contributed much for the development of initiatives and "strong" local leaderships, which a significant part of academic literature in the field defends. Basic and secondary education in particular has been the object strong state regulation, with the central administration determining almost all of its fundamental aspects: curriculum, management and evaluation of schools, training and hiring of professors, evaluation of teachers and students. Despite this, the state has not been aloof of the tendencies of educational reform that have been verified in most Western societies (Silva, 2016, Ball, 2008, 2012):

- advocacy of a strong connection between economy and education while making cultural and social functions in school secondary priority;

- valuation and control of student learning which is considered relevant to the society and economy of knowledge (language, mathematics);

- emergence of new forms of public management, incorporating discursive components and instrumental characteristics of the private sector;

- redefinition of the participation of local actors, increasingly matched to the dimensions of "parental choice" or professional and institutional "self-regulation";

- development of mechanisms of performativity and accountability which greatly limit the autonomy and self-regulation of professionals and schools.

In Portugal, the changes in forms of governance of education, although slow and much subordinated to a century-old logic of centralization, can be identified in diverse tendencies:

-betting on a school contract system, as a form of expressing "autonomy" in schools;

-affirmation of managerial framework models, contradicting the consecrated collegial tradition which followed the democratization of the country (1974);

-appreciation of technical and professional education, entrepreneurship, and orientation towards employability;

-a newsworthy discourse which emphasizes the private sector and systematically devalues public education;

- concentration of financing in education and research to areas where the connection with the business world is more evident.

These new orientations sideliner the fundamental principles that should preside in state schools: equity, citizenship, social justice. The changes in paradigm are particularly visible in the discourse on public education, where private values, work processes, and management instruments become almost unavoidable, despite the specificity of the country in that domain, given that the national business fabric has been tributary of the state initiatives, connections, and support.

\section{Statement of problem, objectives and research methodology}

The creation of the EPIS Association and "Network of Mediators" program can be analysed from different perspectives. The first focuses on a change in the paradigm of governance in education and 
http://dx.doi.org/10.15405/epsbs.2016.11.49

eISSN: 2357-1330 / Corresponding Author: Mariana Dias

Selection and peer-review under responsibility of the Organizing Committee of the conference

Portugal, which has already been referred to, implying an increasing proximity between the educational and economic universes, which presupposes the necessity of reconfiguring the education system in its image. However, the field of intervention chosen by the EPIS Association - the social and educational inclusion of young people - could legitimize other interpretations, particularly the connection to older philanthropic perspectives supporting the more impoverished and vulnerable sectors, with some tradition in the country. In fact, the belated character of the development of the Welfare State in Portugal made it so that many support functions of social solidarity were developed by private institutions, with special relevance for family and the Catholic Church. Facing this dilemma, one of the objectives of this research consists in analysing the intervention and "leadership" that the EPIS Association intends to have regarding the definition of state policies in Portugal and the role of the "Network of Mediators" program in that strategy. We particularly aim to understand whether the Association intends to affirm a new sensibility in the area of education, more business-related, legitimizing the image of public school as change resistant and risk-averse. As such, we will concede great importance to the objectives of the EPIS Association and of the nature of the philanthropic model it defends. In second place, we propose to characterize the model of intervention developed by the "Network of Mediators" and the manner in which it is developed and envisioned on a local level. In order to achieve these objectives, we will employ two complementary research techniques:

- documental analysis of available information pertaining to the EPIS Association and the model of mediation and qualification developed therein;

-semi structured interviews with local actors with more direct involvement in the implementation of the program (head teachers, mediators, local authorities);

The presentation of the results and conclusions of the study will focus on the nature of the philanthropic model which characterizes the EPIS Association as well as the work carried out by the "Network of Mediators" namely on the organizational, social, and community plans.

\section{The guiding principles of the EPIS Association}

The EPIS Association - Entrepreneurs for Social Inclusion was founded in September 2006 by a group of Portuguese entrepreneurs and managers, who accepted a challenge presented by the President of the Republic, Cavaco Silva, which aimed to establish a "national commitment" focusing on social inclusion and the development of a school model built around the idea of innovation. This challenge, which is directed towards the business universe, is a first sign that the creation of the Association is part of a more global framework leading to the change in forms of governance of education . This idea is confirmed by João Render, banker and first president of EPIS who explicitly stated that the birth of the Association is a clear sign of civil society's new attitude toward the challenges of the country and a new model of cooperation between citizens and their sovereign bodies. The choice of "inclusion" and the work with young people in situations of underachievement and school withdrawal, as EPIS's initial area of intervention, could paint this idea, bestowing upon it, as previously mentioned, a greater proximity with the national philanthropic tradition of support towards those who are "down on their luck." In order to understand the intervention approach taken by the EPIS Association, it is important 
to keep in mind that its creation coincides with an important stage in the development of the European Strategy on Education and Training 2010, which considers that the fight against school withdrawal is paramount to making the European Union one of the most developed and competitive economies in the world. Portugal has always had serious problems concerning underachievement and early school withdrawal, which has been the object of several state programs throughout the $20^{\text {th }}$ century (Dias, 2014). Those programs would be reinforced after the definition of this strategy, as shown by various researchers:

"The first decade of the 21 st century was marked in Portugal (...), concerning basic and secondary education, due to the priorities that were defined in the Strategy for Education and Training 2010: improvement of competencies in basic learning, reduction of early school withdrawal, universalization of trends in secondary education among younger students, and the creation of incentives for the development of learning throughout life. These changes illustrate the vital role given to education concerning the policies and priorities of the Union, increasingly centred on the preoccupation and promotion of the competitiveness of the European economy with important effects on the discursive plans and as guideline for the interpretation of reality, the orientation of policies, and the reconfiguring of institutions, educational processes and content, and training."(Belmiro C, Pinhal, J., Martins, J., Rau, M., Dias. M., Afonso ,.N , 2016)

Furthermore, if there were doubts regarding the philanthropic orientation of the EPIS Association, they would easily be dissipated by consulting the Association's website, which clearly expresses the guiding principles and dividing lines concerning other interventions of educational and social nature (see table 1).

Table 1. Main guidelines of the EPIS Association

We Want To Be

Solidarity by qualification

Professionalized model

Direct intervention project

Incubator of new methodologies for the ME "internalize and massify"

\section{We Do Not Want To Be}

Charitable solidarity

Voluntary model

Sponsor of third parties

Competitor or substitute of the ME in the universal service throughout the country

Source: EPIS website (adapted)

\section{The Network of Mediators of Qualification for Academic Success ("Network of Mediators")}

The EPIS Association presents the "Network of Mediators" as an innovative, scientific, and empirically proven program. In the words of the Association, "the EPIS mediators apply a set of evaluation and qualification methodologies for academic success with the help of specialists from several universities, an innovative set of practical methodologies." The intervention involves two main types of methodologies.

- “Selective Methodologies”, implying individual counseling for the student and his/her family, through methodologies referred to as "qualification of educational nature ", although they do not develop curricular activities or direct support in terms of students' school work. The mediators' work focuses on the development of social competencies, which serves as a base for the model and its theoretical framework. 
- “Universal Methodologies” are directed towards the school community and families, and they can take the form of thematic seminars or training sessions (ex: conflict management and mediation, work with parents).

Work in the field is carried out by mediators who can have diversified training - psychologists, mediators, sociologists, professors - and are hired by the various entities that finance the program locally (city halls, associations). The involvement of the school and the Ministry of Education is verified, essentially, by their acceptance and entry in the program and by the creation of work conditions for the mediators:

We have negotiated very little, we have only witnessed the negotiation, we were mere spectators, and we had to accept everything we were given as if we were standing there with our hands out. But the truth is that I am speaking of myself, how I interpreted this as an advantage for the schools and for my school, I have always accepted everything very well, I never put up fences, I have always tried to make our mediators is comfortable as possible, including giving them a place to work, giving them all of the minimum conditions so that they could do a good job, I always did everything in my power so that they could adjust to the other resources, (Head teacher $\mathrm{BJ}$, emphasis added).

In the field, the work process begins by giving every student a survey, an activity known as "screening". Students that are labeled at-risk marked are to have additional interviews for a more indepth evaluation ("zooming"), which is followed by the defining of individual intervention plans. Described in these words, the methodology does not seem very distinct from typical social and educational intervention processes: identification of target public, diagnostic of the situation, and elaboration of intervention plans. As such, it is important to analyze the perspectives of the local actors regarding the program and the role they play.

\section{Mediation in the field: reasons for entry in the program and insight}

The idea that the educational institution requires the support of diverse professionals, beyond professors, to repair the inequality and/or vulnerability among its students has been a significant part of educational policies dealing with "risk population " over the last decades. The concern with access to those resources, which are scarce in many schools, has compelled most of the head teachers interviewed to accept, with greater or lesser reluctance, the role of passive users bestowed on them by the program, despite the importance conceded by EPIS, in other projects, in the leadership of schools (see: Schools of the Future). They do not participate in the selection of the mediators and they are not able to successfully impede their rotation, which support institutions consider to be pertinent following a prolonged period of time in the same school. In this sense, the program distances itself, a great deal, from what academic literature considers being the role of head teachers in the improvement of schools and in the creation of an environment that is suitable for academic success.

As such, it is not surprising that the questioned head teachers should present an image that, albeit a positive one is lacking in detail: they seem unaware of the depth foundations of the model and even of 
some of its operational aspects. As such, most of them tend to resume the "increased value" of the model to the existence of another specialized professional in the institution:

My position regarding this project is extremely positive. To be clear and to the point, the fact that we have one more person working in the school, which is highly qualified, we had two psychologists, at this time we only have one. Naturally, it is always an advantage, regardless of the methodology. (head teacher PL, emphasis added)

Only a minority of interviewed head teachers acknowledge features of this model, which distances itself from other models" it is clear that everything is very organized and that the program has support material of very high quality, in my opinion it is a very good program (head teacher -IM, emphasis added).

As such, the vision for the program rarely surpasses the instrumental and procedural plane. The same can be verified, to a large extent, within the mediators regarding the model. It is considered that the techniques used are in line with what are considered "good practices", recognized by educational psychology. The difference resides in the highly structured nature of the model and of some procedures:

Innovative aspects... I do not believe that there are specific innovative aspects in the methodology because from what I have read, everything I have read about the methodology, most of it I was already aware of. (...) The manual was written by psychologists, so, for me, there was nothing new. One thing worth noting is that they are extremely organized, they're very organized, they work a lot with charts, tables, it's even a way for us to organize ourselves, we know which information we need to gather, in which phase we need to gather it so that we don't run around in circles, which is a waste of time. (mediator MC)

It is mostly the regional coordinators of the program who express, more clearly, the "increased value" of the model:

The mediators know exactly what they have to do and when they have to do it. It is so standardized that they know that they will arrive at school and speak with the students, proceed with the screening, introduce the screening, then the results, then they proceed with the zooming, and after the zooming they proceed with the intervention plan, and then they call the family (...) I believe that is the main advantage because if we count on a team of 10 people, they would arrive at school and each person would do it differently and they would be lost until they found which strategy was best. (EPIS regional coordinator).

Despite its complex and uniform structure, the methodology tends to be considered a value by the mediators, and not like a constraint or limitation concerning their action

They work a lot with charts, tables, it's even a way for us to organize ourselves, and we know which information we need to gather, in which phase we need to gather it so that we don't run around in circles, which is a waste of time. (Mediator. AM)

To this organizing and structured dimension, one can add training and frequent supervision, with the aim of completing objectives and reducing the risk of deviating from the validated methodology:

My work is evaluated, let's say, there is a technical monitoring, weekly, every week we talk, she knows what I'm doing, we are obliged to register the work sessions on the platform, how did the session go, what did we do in that session... (Mediator TC).

Besides the organization and training, the mediators also value the follow-up work that the program frequently offers:

For me, [the most important thing] is the fact that we accompany the student for a period of three years. We begin with the students in the 7th grade. Even if the student is held back, 
he/she is not abandoned; we continue working with the student until he/she finishes the $9^{\text {th }}$ grade. It could be three, it could be four years, and it depends on his progression. And I think that it is very positive because we get to know the family, we already know how the student behaves, and that is very positive, I believe it is the greatest strength of this project. (mediator $\mathrm{JM})$

It is rare, even in the circumstances, to verify full inclusion of the mediators in the institution that receives them. Nevertheless, the coexistence of interventions carried out by different actors does not necessarily imply conflict or friction. The main aspect that emerges from the collected accounts is precisely the emphasis on teamwork and on close articulation. The privileged listeners of the mediators, in the schools, end up being professionals with similar functions: professional orientation services, social workers, class directors. In conjugation with school social technicians, they may proceed to direct students towards diverse services - internal and external, suggesting the existence of local forms of collaboration, albeit punctual and specific:

To me, it always makes sense to work with everyone at all times, when the situation calls for me to direct a student to the Health Centre, I speak with the psychologist because I know that she has a privileged relationship with the Centre. If it is an issue with the CPCJ, I speak with the school's social worker. As such, I don't think it makes sense for a mediator to work alone. (regional coordinator and mediator LC)

In some cases, there are reports of some initial distrust from teachers, which quickly transforms, because any resource that takes weight off of the teachers ends up proving to be of strategic importance in every day school life. This does not mean that mediators have an easy road ahead, and open roads leading toward success:

The mediation that we do with the students, I would like it to be more effective because these students who are demotivated at school, I feel very frustrated sometimes, I mean, when you register on the platform, there is a thing that says "how did the mediator feel after the session, how did the student feel? "Almost every time, I write down that I feel frustrated with the session because it's like this, the student is here, I know that the student is hearing me, and can even agree with what I'm saying, but the fact is that I have a feeling that the student leaves the room and immediately forgets what he/she heard, and tomorrow his/her attitude will be the same. (mediator MC).

In this sense, the work carried out by the mediators of the EPIS Association shows the difficulties that have been identified in other studies, with similar target public and objectives (Lopes, 2012)

\section{Conclusions}

The EPIS Association presents a set of guiding principles that set it apart from traditional forms of philanthropy and social intervention developed in Portugal: it seeks to legitimize itself through processes of regulation by knowledge (links with "experts" and universities); it favours the "scientific character" of the methodologies to "community building" and remits actors and local leaders to a quite passive role; it invests in the creation of its own "brand" (logos, media); it avoids reference to structural social and cultural conditions underlying educational inequalities and school failure presenting these issues in problems that are individual in nature; it defends direct intervention from entrepreneurs in the educational universe in order to ensure innovation and quality in public schools. Curiously, school actors, although not indifferent regarding the media image of the program, they adhere to the same for reasons that contradict the Association's non-assistance-based logic. Essentially, 
they seek to reinforce their human resources: they are not looking, primarily, for innovative methodologies. In fact, the program is seen by many educational actors in a perspective that is essentially instrumental, as a form of access to additional resources that the school needs. The exteriority that the EPIS Association bestows on head teachers when implementing and locally managing the program may help to explain, at least in part, this position. As a consequence the school administrators feel that their role is essentially, limited to the elaboration of work conditions for mediators. The mediators, at school, are mainly in contact with other social professionals and do not have a strong relationship with curricular, pedagogical, or organizational work, which is the main activity of the school. On this basis, it will be difficult for the program to create internal synergies that will guarantee its sustainability beyond the period of financing that was negotiated with the entities that support the program in the field. Moreover, the main objective of the program, the creation of innovative methodologies in this field, which should be adopted and generalized by the Ministry of education, is not yet fulfilled, despite the EPIS Association having a significant number of ex-ministers and other relevant political leaders among their presidents and social bodies. These limitations should not, however, lead one to underestimate the significance and the symbolic role payed by EPIS association in Portuguese society One need only analyze the nature of the social actors that the Association congregates (bankers, entrepreneurs, top-tier political leaders) or that it is able to mobilize to realize that we are witnessing new forms of governance and public action in Portugal that may have a great influence on the future of education in the country, similarly to what has already been observed in other contexts:

Further, it is also important to recognise the discursive and political functions of these networks. Through them new voices are given space within policy talk. (...) The public sector generally is worked on and in by these new policy actors, from the outside in and the inside out. Linkages and alliances around policy concerns and new policy narratives cross between the public and private sectors. New values and modes of action are thus instantiated and legitimated and new forms of moral authority established, and again others are diminished or derided. The practical and financial 'successes' of particular individual entrepreneurs are a particular source of authority and legitimacy here (Ball, 2008, p.3)

It is precisely that network of relationships and interconnections that we propose to identify in future works pertaining to the EPIS Association and similar institutions, in order to have a more indepth understanding of the changes that are taking place regarding the governance of education in Portugal.

\section{References}

Ball, S. (2008) Educational Debate, London: Routledge

Ball, S. (2008) New Philanthropy, New Networks and New Governance in Education. Political Studies, Volume 56, Issue 4, pages 747-765, December 2008

Dias, M. (2014) The impact of Lisbon's Strategy on the patterns of education and training in Portugal, , Procediasocial and Behavioural Sciences, Volume 116, 21 February 2014, Elsevier, Pages 1885-1889. DOI: 10.1016/j.sbspro.2014.01.489

EPIS Website., http://www.EPIS.pt/homepage retrieved in 3.08.2016

Lopes, J.. (2012). Escolas Singulares. Estudos Locais Comparativos. Porto: Edições Afrontamento

Belmiro C, Pinhal, J., Martins, J., Rau ,M ., Dias M and Afonso ,N (2016 ) Organização, Administração e Financiamento da Educação in Silva , M (cor) Pensar a educação II, Lisboa : Educa

Silva , M (2016) (coord) Pensar a educação II, Lisboa : Educa 